\title{
La representación del significado léxico y la movilización de valores sociales: la tarea escolar
}

\author{
The Representation of Lexical Meaning and the \\ Mobilization of Social Values: The Homework
}

\author{
Myriam Castillo Perilla \\ Álvaro William Santiago Galvis \\ Jaime Ruiz Vega ${ }^{1}$
}

Resumen

El artículo centra su atención en el análisis de las representaciones del significado léxico que una muestra de docentes de Bogotá tiene sobre la entidad lingüística tarea escolar. Este análisis se sustenta en los planteamientos teóricos y metodológicos de la Semántica de los Posibles Argumentativos (SPA), en esta medida, el texto presenta los planteamientos básicos de este modelo en lo que respecta al estudio del significado léxico y su relación con los valores y las representaciones sociales que portan las unidades léxicas; así,se parte del presupuesto que señala que por medio de las formas léxicas el hablante, en su actuar lingüístico, lleva a cabo un proceso de axiologización discursiva del mundo. De ahí que el texto aborde, en primera instancia, los supuestos teóricos de la SPA en lo que respecta a la configuración del significado léxico (núcleo, estereotipos, posibles argumentativos) a los despliegues argumentativos; y a los planteamientos de la SPA en relación con la axiologización discursiva, en especial, los conceptos de modalización, modalidad y valor modal, lo cual permite establecer las zonas semánticas modales (ontológica, juicio de verdad, axiológica y valores finalizantes). En segundo lugar, se presentan consideraciones con respecto a los planteamientos metodológicos de la SPA para la reconstrucción del significado léxico a partir de la producción discursiva de los hablantes, lo cual implica trabajo con corpus lexicográficos (diccionarios) y con datos obtenidos de los hablantes (docentes); consideraciones que han orientado el trabajo de reconstrucción de las representaciones que los docentes tienen sobre la entidad léxica tarea escolar.

\section{Palabras clave}

Semántica de los posibles argumentativos, significado léxico, representación, valores, estereotipos lingüísticos, posibles argumentativos.

The paper focuses in the analysis of lexical meaning representations that a sample of teachers from Bogotá has about the lexical entity Homework. To support this analysis the theoretical and methodological approaches of the Semantics of Argumentative Possibilities (SPA) are taken into account. In this regard, the text presents the basic approaches of this model about the study of lexical meaning and its relation with values and social representations that lexical units bear. Thus, it is assumed that through the lexical forms, the speaker, in his lexical performance, conducts a process of discursive axiologisation of the world. Hence, the text first deals with the theoretical approaches of SAP regarding to: Meaning configuration of lexicalmeaning (core, stereotypes, argumentative possibilities) and argumentative displays; the theoretical approaches of SAP regarding the discursive axiologisation, specially the concepts of modalisation, modality and modal value, which leads to establish the semantic modal zones (ontological, truth judgment, axiological and ending values). Then, considerations are presented regarding the methodological approaches of SAP for the reconstruction of lexical meaning from the discursive production of speakers. This implies a work with lexicographical corpus (dictionaries) and with data obtained from speakers (teachers), considerations that had oriented the reconstruction work of representations that teachers have about the lexical entity Homework.

1 Universidad Pedagógica Nacional, Bogotá, Colombia. Correos electrónicos: mcastillo@pedagogica.edu.co; asantiago@pedagogica.edu.co; jruiz@pedagogica.edu.co. Integrantes del Grupo de Investigación en Pedagogía, Lenguaje y Comunicación, GIPELEC. 
Semantics of Argumentative; Possibilities, lexical meaning, representations, social values, linguistic stereotypes, argumentative potentials.

Artículo recibido el 14 de abril de 2014 y aprobado el 20 de agosto de 2014.

Los planteamientos que se exponen en este trabajo corresponden a parte de los desarrollos conceptuales y metodológicos que sustentan el proyecto de investigación La movilización discursiva de valores sociales asociados a la entidad léxica tarea escolar en la educación básica y media en Bogotá, DLE-36113.Este proyecto tiene como finalidad identificar $y$ analizar las concepciones que de las tareas escolares tienen los docentes de la educación básica y media de Bogotá. En esta medida, busca dar cuenta del interrogante: ¿Cuáles son los valores sociales y las representaciones del significado léxico que los docentes de lengua de los ciclos 1 a 5 de la ciudad de Bogotá tienen con respecto a la entidad léxica tarea escolar? Esto teniendo en cuenta que son los docentes los sujetos generadores de las tareas, por esta razón es el actor elegido para indagar por las representaciones que se convierten en la base y en la justificación de la asignación de las actividades denominadas tareas, así como en el proceso que puede desprenderse de estas.

El análisis de dichas representaciones se fundamenta, tanto en lo conceptual como en lo metodológico, en los postulados que ofrece el modelo de la Semántica los Posibles Argumentativos (SPA). ${ }^{2}$ Atendiendo a este último aspecto, este artículo ofrece los fundamentos teóricos que sustentan el trabajo de la SPA y la orientación metodológica que esta opción de análisis ofrece para estudiar los valores y las representaciones sociales que portan las entidades léxicas; asimismo, da cuenta de algunos de los resultados que ha arrojado el trabajo.

2 Las citas expuestas en este documento corresponden en su gran mayoría a la traducción realizada por los autores a partir de las fuentes publicadas en lengua extranjera.

\section{La SPA y el análisis de las prácticas humanas}

De acuerdo con Galatanu (2000a), la investigación de las acciones humanas, especialmente el sentido que los sujetos sociales asignan a sus actos y a sus dinámicas de identidad, encuentra un lugar privilegiado en el análisis del discurso, dado que favorece la reducción de la subjetividad de quien analiza e interpreta lo factual social. Este planteamiento se fundamenta en el postulado que sostiene que la idea que el ser humano tiene de sí y del otro, así como de las relaciones intersubjetivas, de los objetos del mundo y de todo cuanto en ello existe, pasa por su discurso.

El carácter social de la lengua permite dar cuenta de los significados compartidos por una comunidad lingüística. Esta dimensión social favorece entonces la interacción de los sujetos que constituyen esa comunidad y, de esta manera, la reconstrucción de la realidad sociocultural (Ruiz, 2011, p. 75). Ahora bien, esta interacción se encuentra lejos de limitarse a la descripción o a la narración de lo que sucede en el mundo. En consecuencia, el hablante, a través de su acción discursiva, expone su concepción del mundo, la visión que tiene de lo que en él ocurre, al igual que la imagen que tiene de los otros y el valor que asigna a los componentes de su realidad. Así, a través de las entidades léxicas que pone en acción en su discurso, el hablante revela la valoración que hace de las cosas y de los seres. Esto se da gracias a la dimensión argumentativa que caracteriza el sistema verbal. Al decir de Vignaux (1988, p. 115):

Toda actividad de lenguaje construye de manera permanente entre, de un lado, lo delimitado, lo nombrado, lo estabilizado y, de otro lado, lo no delimitado, lo no definido que esta misma actividad introduce con el fin de desplazar las referencias 
de conocimiento o de comprensión establecidas $y$, por ende, de negociar representaciones nuevas o personales de las cosas.

Esta actividad desencadena al mismo tiempo un proceso que se puede denominar axiologización discursiva del mundo. Este proceso, en términos generales, consiste en la valoración que el sujeto realiza de lo que habita en el mundo, de tal suerte que le imprime a la realidad una serie de valores que no forman parte de su ontología y que corresponden a la representación que el individuo elabora de su entorno (natural, social o cultural). Esta valoración está presente o se activa en cada entidad léxica que el hablante emite y a través de estas da cuenta de sus representaciones.

Para analizar este proceso desde la óptica de la SPA, se hace necesario abordar la problemática del significado léxico, porque es gracias a este que se busca dar cuenta de las representaciones y de la movilización de valores en la acción discursiva del sujeto.

El significado léxico se asume como "una conceptualización ampliamente idéntica de un individuo a otro, lo cual da origen a una especie de base para una inter-comprensión lograda" (Kleiber, citado por Galatanu, 2003a, p. 215). Al respecto, Galatanu agrega que este significado tiene como función la "estabilización del mundo en la lengua” (2003a, p. 215). La Semántica de los Posibles Argumentativos (SPA) establece que el significado léxico se caracteriza por lo convencional y duradero de la asociación que se genera entre una representación y una expresión verbal. Estas consideraciones llevan a que, desde esta perspectiva teórica, se defina el significado como:

La(s) representación(es) asociada(s) a una expresión verbal de manera duradera en una comunidad lingüística (mediante convención de la institución lingüística a la manera de Searle) [...] y que corresponde más o menos, o al menos, al lugar que tendría en el triángulo de Ogden y Richards [...] al significado de Saussure [...], al interpretante de Peirce [...], a la referencia de Ogden y Richards (1923), a la designación de Morris (1938). (Galatanu, 2000a, p. 29)

En cuanto al sentido discursivo, Galatanu afirma que este "designa [...] la asociación de dos o varias representaciones propuestas por un sujeto hablante en un acto discursivo, necesariamente singular, en una situación necesariamente inédita" (2000a, p. 29). Como se puede observar, la asociación, el papel del sujeto hablante-pensante y la inserción de este último en el discurso, son aspectos fundamentales para la definición del sentido desde la perspectiva teórica de la SPA.

De lo anterior y de otros aspectos indispensables para estudiar cómo se inscribe el sujeto hablante en su discurso y cómo activa, invierte, refuerza o debilita los valores convocados en las entidades léxicas, se ocupa la SPA.

\section{Elementos de la SPA}

Inspirado en las ideas de Putnam (1975) sobre el significado de las palabras, y en la misma orientación de la semántica argumentativa (Anscombre y Ducrot, 1994; Carel y Ducrot, 2005), el enfoque propuesto por la SPA se muestra como holístico, asociativo y enciclopédico. A partir de las propuestas de Putnam que presentan el significado en términos de núcleo y de estereotipos, Galatanu desarrolla un modelo de descripción del significado léxico, conformado por tres estratos: núcleo, estereotipos y posibles argumentativos. Estos estratos se definen y describen desde una perspectiva argumentativista. Frente a una perspectiva descriptivista, la argumentativista da cuenta del potencial de orientación discursiva de las entidades léxicas. En este orden de ideas, se apunta al potencial argumentativo de las palabras y a las diferentes asociaciones que se generan entre estas.

A los citados estratos del significado léxico, Galatanu agrega una forma de manifestación discursiva, denominada por esta autora como los despliegues argumentativos. Estos despliegues sitúan el modelo en la interface de la lengua y del discurso. En términos generales:

- El núcleo corresponde a los rasgos de categorización semántica, descritos por Putnam (1975) como el elemento estable del significado léxico. 
La SPA considera estos rasgos como "propiedades esenciales".

- Los estereotipos son "un conjunto abierto de elementos del núcleo con otras representaciones y que constituyen bloques de argumentación interna" (Galatanu, 2009b, p. 395).

- Los posibles argumentativos obtienen su existencia de la asociación de la entidad léxica con uno de los elementos de su estereotipo y corresponden a secuencias discursivas que son calculadas a partir de los estereotipos que constituyen esta unidad. Estas probabilidades argumentativas existen en bloques de argumentación externa, son asociaciones virtuales que "se organizan en dos haces orientados respectivamente hacia uno o el otro de los polos axiológicos (positivo y negativo)" (Galatanu, 2005a, p. 57). El entorno semántico o el contexto producen una contaminación discursiva que genera, a su vez, la orientación positiva o negativa del haz de asociaciones. Según su organización en dos haces, los posibles argumentativos pueden ser conformes o no conformes a la orientación axiológica del estereotipo.

- Los despliegues argumentativos, o forma de manifestación discursiva, "son las secuencias argumentativas realizadas por las ocurrencias discursivas" (Galatanu, 2009b, p. 396). Este nivel, presente solamente en el discurso, apunta a la actualización de los posibles argumentativos. Estos posibles argumentativos permiten relacionar el sentido de las ocurrencias discursivas y el significado de la unidad léxica y de verificar, luego, la conformidad o la noconformidad de este sentido con el protocolo semántico del significado.

Para ilustrar lo anterior, a continuación se expone la representación del significado léxico de la entidad éxito. El núcleo y los estereotipos identificados resultan del análisis de lo que se denomina discurso lexicográfico o definiciones que aparecen en los diccionarios. Para el caso del ejemplo se encontró en estos discursos lo siguiente:
El $\mathrm{DBCI}^{3}$ define la palabra éxito como: " $\mathrm{m}$. Buen resultado de una empresa, acción o suceso. (Aprobación del público)". Para el DLEE, ${ }^{4}$ el éxito corresponde a "[...] Resultado feliz". El due ${ }^{5}$ presenta la siguiente definición:

m. Resultado, bueno o malo, de una empresa, una acción o un suceso: 'Ha terminado los exámenes con buen éxito. Tiene mal éxito en todo lo que emprende' - Corrientemente, se emplea sin ningún adjetivo y significa "resultado favorable": 'Tuvieron éxito sus gestiones. El éxito le acompaña por donde va' • (inf.) Por ejemplo, en las relaciones amorosas: 'Es una chica de mucho éxito. Tiene mucho con los chicos. Partido. • ("Tener") *Partidarios entre la gente: 'Esa moda no ha tenido éxito'. Aceptación.

Por último, el DRAE6 lo define como: "1. m. Resultado feliz de un negocio, actuación, etc. 2. m. Buena aceptación que tiene alguien o algo. 3. m. p. us. Fin o terminación de un negocio o asunto".

Del conjunto de definiciones y, específicamente, de los rasgos comunes se obtiene el estrato denominado núcleo. En cuanto a los estereotipos, estos provienen de los ejemplos y citas que los diccionarios utilizan para ilustrar las definiciones. En la tabla 1 se observa, entonces, que el núcleo retoma los elementos presentes en las definiciones y que está constituido por cuatro bloques de significado, vinculados entre sí por la relación normativa PLT (Por Lo Tanto). Estos bloques se presentan como elementos estables en el significado de la palabra éxito en lengua española, lo que hace que en general todos los hablantes reconozcan esa entidad lingüística como lo que es: querer obtener algo PLT acción PLT obtener algo PLT aceptación/renombre. En la columna de los estereotipos se presentan algunos de los elementos que conforman el conjunto abierto de asociaciones. Cabe señalar que los puntos suspen-

3 Diccionario Básico Castellano llustrado.

4 Diccionario de la Lengua Española Educar.

5 Diccionario de Uso del Español.

6 Diccionario de la Lengua Española. Academia de la Lengua Española (drae). 
sivos al final de la columna representan el carácter de estrato sin límites y modificado culturalmente.

Tabla 1. Representación del significado de la entidad léxica éxito

Núcleo

\begin{tabular}{|c|c|}
\hline $\begin{array}{l}\text { LT } \\
\text { cción } \\
\text { LT } \\
\text { btener algo } \\
\text { un resultado) } \\
\text { LT } \\
\text { ceptación/renombre }\end{array}$ & $\begin{array}{l}\text { PLT tentativa } \\
\text { PLT culminación } \\
\text { PLT resultado bueno } \\
\text { PLT aceptación/aceptado } \\
\text { por la gente } \\
\text { PLT felicidad }\end{array}$ \\
\hline
\end{tabular}

De otro lado, se debe tener en cuenta que los elementos del núcleo (por ejemplo, querer obtener algo) se relacionan con los de los estereotipos (tentativa, culminación, resultado bueno, felicidad...) en bloques de argumentación interna del tipo: Éxito: querer obtener algo PLT tentativa, culminación, resultado bueno, felicidad...

En cuanto a los posibles argumentativos, se calculan al poner en relación la palabra éxito con elementos de los estereotipos en bloques de argumentación externa: Éxito PLT tentativa, culminación, resultado bueno, felicidad...

Como enfoque asociativo y holístico del significado, la teoría de la SPA asume los estereotipos de una entidad léxica como representaciones de las "asociaciones, en bloques de significado argumentativo (relación propuesta como una 'relación natural': causa-efecto, síntoma-fenómeno, fin-medio, etc.) de los elementos del núcleo con otras representaciones semánticas" (Galatanu, 2005a, p. 57). La identificación concreta de los límites rígidos de los conjuntos abiertos, formados por estas asociaciones "relativamente estables" en el interior de una comunidad lingüística en un momento dado de la evolución de su lengua, es imposible.

A partir de esta condición, el enfoque de la SPA se define como enciclopédico "puesto que todos los aspectos de nuestro conocimiento de la entidad en juego contribuyen al sentido de la expresión que la designa” (Galatanu, 2005a, p. 57). Y, de manera más general, todos los conocimientos que hemos interiorizado y que hacen parte del capital indivi- dual y cultural nos permiten navegar en el tejido sociocultural e intercultural mediante, entre otros, las lenguas, y contribuyen al análisis del significado léxico. En torno a este tema, Galatanu establece que "todos los aspectos de nuestro conocimiento participan igualmente en la reconstrucción discursiva del significado léxico gracias al fenómeno de 'decoherencia' y de la 'contaminación' semántica y/o pragmática" (2005b, p. 193).

La SPA se presenta como un modelo que se funda sobre tres hipótesis y que está constituido por tres estratos y "una forma de manifestación discursiva, en total 4 niveles" (Galatanu, 2009b, p. 394). A lo expuesto se debe agregar que en la misma orientación de la semántica argumentativa presentada por Anscombre y Ducrot (1994), el modelo SPA establece como postulado que el sentido de los enunciados es argumentativo y establece como hipótesis que este sentido "se apoya en y (re)inscribe con cada ocurrencia discursiva, un potencial axiológico (por lo tanto argumentativo) en el significado de las entidades léxicas" (Galatanu, 2009b, p. 394).

Esta hipótesis se refiere al hecho de que el ser humano inscribe su percepción del mundo en las entidades léxicas $y$, orientado en cierta forma por su cultura, por sus experiencias, su vida y su formación, evalúa este mundo y las relaciones que allí se desarrollan. De esta manera, el sujeto refuerza o actualiza el significado de estas entidades lingüísticas en la acción discursiva. Cabe agregar que con la puesta en discurso de las entidades léxicas, el individuo puede hacer cambiar el significado que les asigna a las palabras que utiliza para insertarse en la realidad; especialmente, modifica los estereotipos (y entonces los valores) asociados a dichas palabras.

La segunda hipótesis establece que el potencial axiológico de las entidades lingüísticas, que existe en forma "de asociaciones en bloques semánticos de argumentación" (Galatanu, 2009b, p. 394), se caracteriza por su anclaje cultural. Esta base cultural le imprime igualmente su carácter evolutivo y al significado léxico un cinetismo ${ }^{7}$, incluso si el núcleo está

7 El cinetismo, que hace referencia al carácter dinámico, transformable del significado léxico, es definido por Galatanu como la di- 
libre de modificaciones en razón a sus características establecidas sobre universales y primitivos semánticos o tal y como lo manifiesta Galatanu (2009a, p. 56): “[...] un núcleo estable, que podemos representar en términos de universales y de primitivos semánticos [...]".

El anclaje denotativo, referencial, aparece en el núcleo y en los estereotipos, estos últimos también anclados culturalmente y, por lo tanto, susceptibles de evolución y cambio. Esta tercera hipótesis tiene como marco el lenguaje "aprehendido como herramienta cognitiva, de representación del mundo 'percibido y modelado' [...] por la lengua, mediante significados lingüísticos" (Galatanu, 2009b, p. 394). Es la asociación de las representaciones del núcleo, y de sus elementos, con las de los estereotipos lo que produce la dimensión argumentativa. Esta dimensión se manifiesta igualmente en los bloques de argumentación externa, esto es, a nivel de posibles argumentativos o de secuencias discursivas formadas por la asociación de la entidad léxica con elementos de su estereotipo.

\section{El dispositivo de significado}

En la SPA, un dispositivo de significado origina los posibles argumentativos. Este dispositivo está constituido por el núcleo y los estereotipos de las entidades léxicas analizadas. Un dispositivo de este tipo se construye "a partir de los enunciados expuestos en las definiciones léxicas y de los ejemplos propuestos por los diccionarios" (Galatanu, 2009b, p. 394) como ya se señaló. En cuanto a los despliegues argumentativos, estos existen en un contexto mediante las ocurrencias discursivas. Por lo tanto, es en la puesta en discurso de las entidades léxicas $y$ en sus interacciones que aparecen los despliegues argumentativos, lo cual presenta al discurso como un fenómeno observable reivindicado por la SPA.

Ahora bien, el modelo de la SPA establece cuatro condiciones que deben observarse con el fin

námica de ese significado, esto es "su reconstrucción permanente mediante mecanismos semánticos y pragmáticos ejecutados por los discursos de los hablantes" (2006, p. 90). de elaborar de manera adecuada la representación semántica (Galatanu, 2007, p. 316):

- "Esta representación debe contener una dimensión descriptiva del significado léxico [...]",

- Esta representación debe mostrar tanto la "parte estable" del significado como la parte evolutiva, que el discurso propuesto carga y/o descarga de valores;

- Dar cuenta del estatuto de conjunto abierto de elementos de significado evolutivos o "estereotipos";

- Dar cuenta del potencial discursivo (argumentativo) del significado léxico.

A partir de las hipótesis expuestas antes, así como de los estratos y de las condiciones que define, la SPA propone un "modelo de la construcción del significado léxico y de la reconstrucción discursiva del significado léxico a partir de las hipótesis formuladas en y por la interpretación del sentido de diferentes ocurrencias de empleo de los lexemas involucrados" (Galatanu, 2007, p. 314).

\section{La semántica de los posibles argumentativos y la axiologización discursiva}

Cuando el investigador analiza las palabras emitidas por un individuo, ya sea que para ello utilice el sistema verbal o el escrito, no busca determinar si estas palabras son verdaderas o falsas, sino la manera como este sujeto se presenta el mundo a través de su realización discursiva. $\mathrm{Al}$ respecto, Dervin afirma que "el análisis del discurso no se enfoca en saber si tal o cual enunciado es verídico sino que se interesa ante todo en las representaciones que están presentes en el discurso" (2009, p. 170).

En un intento por relacionar las modalidades y la actividad del profesor en clase de lengua extranjera, Dervin subraya que Le Querler insiste en la importancia de abordar las modalidades con el fin de favorecer el desarrollo de una identidad móvil (flexible), 
Le Querler, en su libro Tipología de las modalidades (1996), propone interesarse en las modalidades alética (posible, imposible, necesario y contingente), modalidades deónticas (deber), modalidades temporales, modalidades subjetivas (epistémicas), modalidades intersubjetivas y modalidades implicativas (una proposición implica otra). Estos elementos favorecerán la puesta en escena del sujeto mismo y del Otro y, por ende, la co-construcción de la identidad móvil de los individuos en un contexto intercultural. Si el estudiante aprende a identificar estas marcas enunciativas, podrá mejorar en el control de su propio discurso y evitar la escenificación diferencialista-culturalista, así como tener un impacto en las actitudes y actuar/reaccionar de manera ética frente a la alteridad. (Dervin, 2009, p. 170)

Las contribuciones anteriores enriquecen la construcción de la competencia intercultural y la inter-comprensión, pero se hace necesario avanzar en el desarrollo de procesos que lleven a ello. De estos aspectos tratados por Dervin es preciso retomar lo referido a las modalidades, en la medida en que están estrechamente relacionadas con la axiologización del mundo mediante la lengua hecha discurso. De manera tangencial al objetivo definido en el presente documento, es preciso anotar que el tratamiento de estas modalidades en clase de lengua contribuiría a construir una competencia comunicativa más sólida, lo que, a su vez, permitiría al estudiante la diferenciación de los valores presentes en su discurso y en el de los otros.

\section{La axiologización discursiva}

El lenguaje, actualizado en la lengua, permite no solo la descripción del mundo sino, sobre todo, la evaluación de las representaciones del mundo que el hombre construye. El hablante inscribe entonces en su expresión, y comenzando por las entidades léxicas —en razón a su potencial argumentativo-, "evaluaciones, ligadas, referidas a campos de experiencia humana” (Galatanu, 2003a, p. 217). Existen, por lo tanto, mecanismos lingüísticos mediante los cuales el hombre se construye él mismo y construye el mundo, de un lado, y realiza evaluaciones de sí mismo y del mundo que ha construido, del otro. Esta construcción y esta evaluación se realizan en y por el discurso. Al respecto, Galatanu establece como hipótesis que

El discurso, aunque no tenga como objeto los valores, los problemas de ética, de moral, de deontología, o como objetivo la transmisión, el refuerzo o también la reconstrucción de un sistema de valores, no es menos evaluativo de la representación que él propone del mundo y, por consiguiente, portador de valores. (2000, p. 87)

En este orden de ideas, el análisis del discurso permite dar cuenta tanto de 1) "la presencia de los sistemas de valores" en los discursos descriptivos, analíticos y teóricos sobre los valores, y en los que tienen por objeto la transmisión de estos valores, como de 2) la "dimensión edificante" presente en cualquier tipo de discurso (Galatanu, 2000, p. 88). En el primer caso, se trata de los discursos que Galatanu denomina edificantes y que tienen por objeto los valores y como finalidad su preservación o su adquisición. Igualmente, este caso concierne a los discursos que se refieren "a los valores, a sus orígenes, a su respeto y a su transgresión” (Galatanu, 2000 , p. 88.), sin que por ello se busque preservarlos, transformarlos o respetarlos o hacerlos respetar. Por lo tanto, en estos dos niveles los valores son objeto de estudio del lingüista y a los que es necesario agregar un tercero que se refiere al carácter argumentativo de los discursos; para Galatanu, "la dimensión argumentativa de todos los discursos, inscrita en el significado de las unidades léxicas movilizadas o construida en contexto, autoriza una orientación axiológica (negativa o positiva) de los encadenamientos discursivos que éste [el significado] hace posible" (2000, p. 88).

En su texto La construction discursive des valeurs, Galatanu (2003b) aborda tres fuentes de su reflexión sobre el tema que la ocupa. La primera está relacionada con la diversidad de discursos sobre los valores en todas las prácticas sociales, lo que provee al lingüista de corpus ricos y variados que dan cuenta de la deconstrucción y reconstrucción de los sistemas de valores y que permiten estudiar los nexos 
entre las prácticas humanas y los discursos que éstas generan. Galatanu afirma que esta realidad invita al investigador a replantear la problemática de los valores (definición, origen, generalidad, universalidad y circulación de los sistemas de valores) en una perspectiva lingüística.

La segunda fuente tiene que ver con el discurso como portador de valores ya que favorece no solamente la construcción del individuo y del mundo, sino también la evaluación de estos resultados de la construcción. En consecuencia, el discurso axiologiza este mundo construido. El discurso, al ser portador de valores, se convierte en el objeto de análisis del lingüista. Para llevar a cabo esto, el investigador se impone como tarea la formulación de hipótesis sobre la naturaleza edificante del discurso, su carácter evaluador y "sobre los mecanismos que ejecuta para 'axiologizar' el mundo que este discurso construye" (Galatanu, 2003b, p. 88). Por lo tanto, en el terreno de la SPA, deben estudiarse los conceptos de modalización y de valor modal propuestos por la lingüística con el fin de analizar la toma de posición del sujeto enunciador en y por su discurso. En este sentido, y en el campo de la semántica, el modelo de la SPA está en capacidad de mostrar que las entidades léxicas pueden tener uno o varios valores modales entre los elementos de sus estereotipos o incluso de sus núcleos.

En cuanto a la tercera fuente, en relación con la dimensión argumentativa de todos los discursos, esta corresponde al "interrogante sobre el funcionamiento de las entidades léxicas en la construcción del sentido discursivo, en sus nexos con un modelo de descripción en semántica léxica" (Galatanu, 2000, p. 88-89), y también con el interrogante sobre los conceptos utilizados en la descripción del potencial argumentativo de la lengua. De lo expuesto deriva la exigencia de una articulación del análisis del discurso con un enfoque semántico teórico que pueda dar cuenta del potencial axiológico de las palabras. En este orden de ideas, es importante comentar que Galatanu se propone revisar el concepto de modalidad y de respaldar "una 'entrada' semántica en este campo de la lingüística" (2000, p. 89).
Ahora bien, al tratarse, en este caso, de un estudio del significado léxico con miras a dar cuenta de los valores sociales activados por los profesores de Bogotá, este debe enmarcarse en el campo de la lingüística y se requiere recurrir a un enfoque lingüístico de la noción de valor. Este enfoque lingüístico, desarrollado a la luz de la semántica argumentativa, se funda sobre estos tres conceptos:

- La modalización que se origina en el análisis del discurso.

- La modalidad que hace parte de la teoría lingüística de las modalidades.

- El valor modal "que proviene de un enfoque semántico de las modalidades" (Galatanu, 2002, p. 20).

\section{Galatanu define la modalización discursiva como}

La inscripción en el enunciado, mediante una marca (huella) lingüística (formas modales), de la actitud (valor modal) [intelectual, volitiva, evaluativa] del sujeto comunicante respecto del contenido proposicional de su enunciado y de la función que este enunciado está llamado a tener en la interacción verbal en la que el sujeto participa. (Galatanu, 2002, p. 20)

Es así como la movilización de las formas lingüísticas o formas modales y la convocación de algunas tomas de posición, o valores modales, favorecen la aparición de funciones discursivas que actualizan la modalización. Esta caracterización debe recurrir a las definiciones de valor que provienen de las ciencias humanas y sociales, las cuales dan cuenta de su carga subjetiva. Entonces, el valor que el individuo asigna a un aspecto del mundo se estructura sobre el interés, la ruptura de la indiferencia, una elección, una afinidad y una toma de partido. Este valor está ligado a la concepción del mundo del sujeto pensante y actor, así, "todo valor se inscribe de esta manera en el eje positivo/negativo para evaluar y jerarquizar las cosas" y "los valores tienen una carga positiva" (Galatanu, 2000, p. 91) y remiten a un ideal, al bien y aun a la norma, y estos valores pueden cambiar según la cultura, así como en función de su forma y de su contenido. 
Si se tiene en cuenta esta importancia de los valores, el investigador debe estudiar su enunciación mediante "mecanismos argumentativos que hacen aparecer valores inscritos de manera relativamente estable en el significado de las palabras" (Galatanu, 2000, p. 91). Pero estos mecanismos pueden ir más lejos, en la medida en que pueden deconstruir el significado de las entidades léxicas portadoras de valores axiológicos y al mismo tiempo debilitarlos, neutralizarlos, invertirlos. Los trabajos de Galatanu han permitido relanzar tanto el valor del papel de la lengua en la aparición de los valores como los "mecanismos de propagación de los sistemas de valores" (2000, p. 92).

Como se expuso anteriormente, la SPA aborda tres conceptos fundamentales para el análisis de los valores en el discurso y en la lengua. El concepto de modalización, del campo del análisis del discurso, corresponde al de modalidad en el terreno de la teoría lingüística. ${ }^{8}$ Luego de aparecer en el ámbito de la lógica y de la lingüística modales, tanto como el concepto de valor modal, el de modalidad se desarrolló y su amplitud permitió pasar de la toma en consideración de la actitud del sujeto respecto del contenido del enunciado (y que equivale en la SPA a la modalización de enunciado) a la recuperación de los elementos que marcan la fuerza ilocucionaria de los enunciados (y que corresponden en la SPA a la modalización de enunciación) y de numerosos elementos que traducen el juicio de valor que realizan los sujetos hablantes sobre los predicados de los enunciados: calificantes de los sustantivos y caracterizantes de los verbos (modalidades de re). En estas últimas, Galatanu (2000, p. 91-92) introdujo igualmente los predicados nominales (de los sustantivos) y verbales (de los verbos o expresiones verbales) que portan un valor modal en su significado y pueden modalizar el enunciado, simplemente porque aparecen en el citado enunciado.

8 En lingüística, la modalidad se asume como un fenómeno discursivo que se "refiere a cómo se dicen las cosas; es decir, a la expresión verbal o no verbal de la visión del locutor respecto al contenido de sus enunciados [...]. La modalidad es un concepto que se refiere a la relación entre el Locutor y los enunciados que emite" (énfasis del original) (Calsamiglia y Tusón, 1999, p. 174). Esta toma de posición o evaluación de la expresión se hace evidente, desde luego, en las formas léxicas que utiliza el hablante.
En cuanto a la modalidad, corresponde a la "forma lingüística activada para expresar, marcar esta actitud [del sujeto hablante] o valor modal, como el resultado lingüísticamente marcado del proceso de modalización” (Galatanu, 2000, p. 93). Estos tres conceptos se presentan así:

- Modalización: Proceso de inscripción.

- Modalidad: Forma lingüística activada, forma modal.

- Valor modal: Actitud, toma de posición.

El estudio del investigador para dar cuenta de la evaluación del mundo como resultante de la acción discursiva (funciones modales discursivas) tiene en cuenta la intersección del "análisis de los valores modales convocados y de las formas modales (modalidades [de rey modalidades de dicto]) activadas" (Galatanu, 2000, p. 93). En la tabla 2 se presenta un resumen de las funciones modales discursivas que resultan del cruce de los contenidos semánticos activados y portadores de valores modales con las formas lingüísticas activadas:

\section{Las zonas semánticas modales}

Se hace necesario recordar que en el enfoque lingüístico de los valores propuesto por Galatanu, uno de los conceptos claves es el de valor modal que equivale a la actitud del sujeto (pensante, hablante y actor) frente al "contenido proposicional de su enunciado y de la función que este enunciado cumple aparentemente en la interacción verbal en la que participa" (Galatanu, 2003b, p. 90). Estos valores modales se materializan en las formas modales activadas en el discurso del sujeto comunicante. Estas actitudes, estas apreciaciones o evaluaciones portadas por las formas modales del enunciado del hablante están agrupadas en cuatro zonas semánticas modales, tal y como aparecen en el esquema de la modalización discursiva: zona modal ontológica, zona modal de juicio de verdad, zona modal axiológica y zona modal de los valores finalizantes. 
Tabla 2. La modalizacióndiscursiva

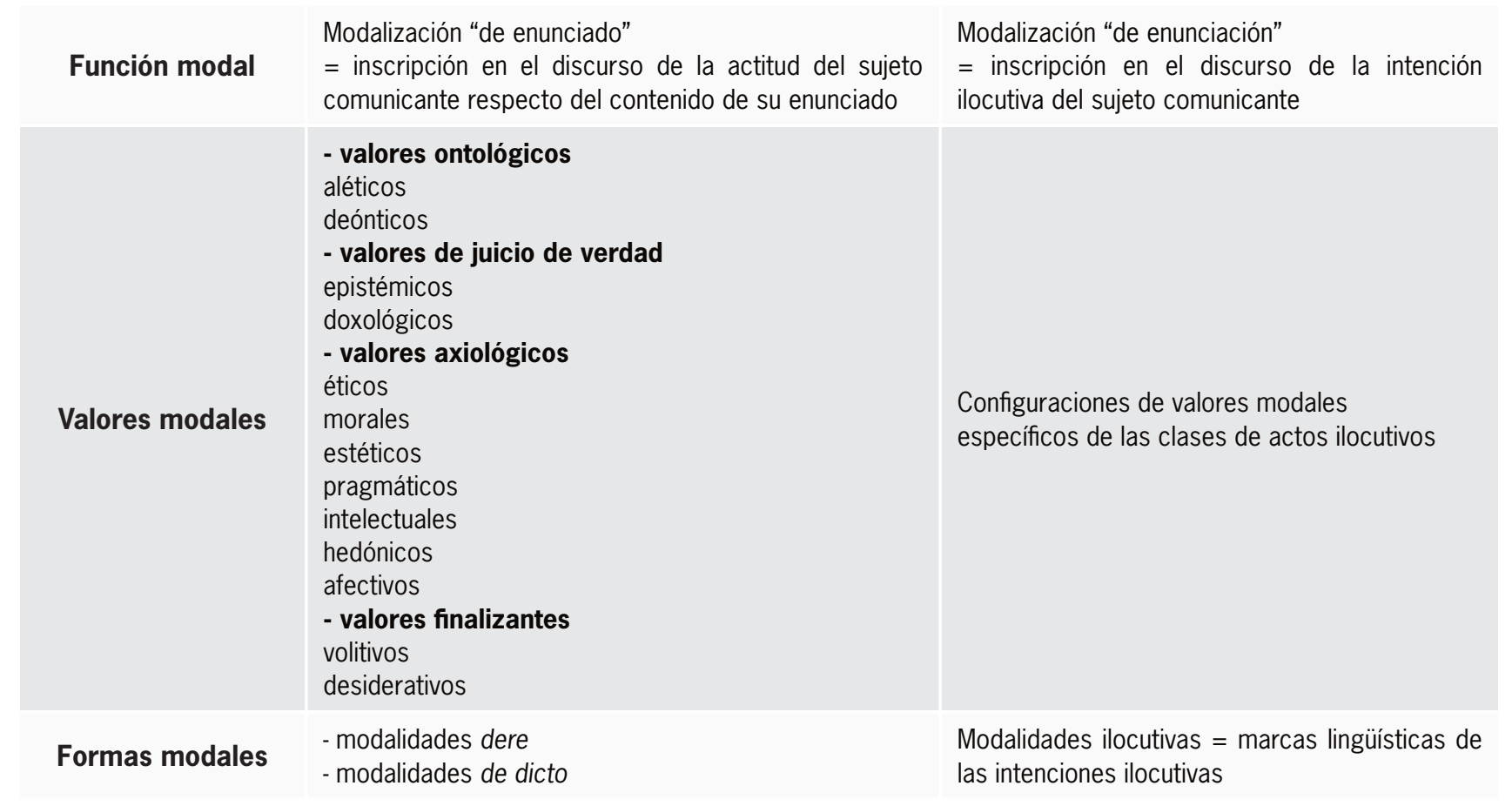

Fuente: Galatanu, 2003b, p. 94

\section{La zona modal ontológica}

Los valores ontológicos remiten a los valores existenciales que dan cuenta de la realidad perceptible del mundo natural y social, los dos representados en y por el discurso. En esta zona modal se inscriben los valores aléticos y los valores deónticos.

Los valores modales aléticos corresponden a la actitud modal de la aprehensión "del funcionamiento de las leyes naturales" (Galatanu, 2000, p. 94). En la misma orientación de las modalidades proposicionales de Parret (citado por Darrault, 1976, p. 6), especialmente las aléticas, la base de estos valores es la palabra necesario, los otros términos se definen al negar esta palabra de base, como se expone en la tabla 3:
Tabla 3. La base de los valores aléticos

\begin{tabular}{|l|l|}
\hline \multicolumn{1}{|c|}{ Necesario } & \multicolumn{1}{|c|}{$\begin{array}{l}\text { Contingente } \\
\text { (no necesario) }\end{array}$} \\
\hline $\begin{array}{l}\text { Posible } \\
\text { (no necesario que no) }\end{array}$ & $\begin{array}{l}\text { Imposible } \\
\text { (necesario que no) }\end{array}$ \\
\hline
\end{tabular}

Fuente: Darrault, 1976; Galatanu, 2000.

Por lo tanto, estos valores modales corresponden a: $\langle$ necesario $\rangle$, <imposible $\rangle$, $<$ posible $\rangle$, $<$ aleatorio $>$. A partir de la orientación de Galatanu (2003b, p. 94-95), esta zona modal se puede presentar como aparece en la tabla 4 : 
Tabla 4. Valores aléticos: < necesario >

\begin{tabular}{|c|c|}
\hline $\begin{array}{c}<\text { necesario }> \\
\text { deber ser }\end{array}$ & $\begin{array}{l}\text { <imposible> } \\
\text { No deber ser } \\
<\text { <ecesario > } \\
<\text { deber no ser> }\end{array}$ \\
\hline $\begin{array}{c}<\sim \text { necesario } \sim> \\
\text { lo que no es necesario } \\
\text { valor }<\text { posible }> \\
<\text { no deber ser }>\end{array}$ & $\begin{array}{c}<\sim \text { necesario }> \\
<\text { contingente, aleatorio }> \\
<\text { no deber ser }>\end{array}$ \\
\hline
\end{tabular}

Fuente: Galatanu, 2003b.

Los valores deónticos se refieren a las normas o reglas sociales. Estos aluden a la organización social, a las convenciones que la sociedad ha creado e impuesto para garantizar su buen funcionamiento; se estructuran sobre la base de la palabra obligatorio, como se presenta a continuación (Tabla 5):

Tabla 5. La base de los valores deónticos

\begin{tabular}{|c|c|}
\hline Obligatorio & $\begin{array}{c}\text { Opcional } \\
\text { (no obligatorio) }\end{array}$ \\
\hline $\begin{array}{c}\text { Permitido } \\
\text { (no obligatorio que no) }\end{array}$ & $\begin{array}{c}\text { Prohibido } \\
\text { (obligatorio que no) }\end{array}$ \\
\hline
\end{tabular}

Fuente: Darrault, 1976; Galatanu, 2000.

De lo anterior se desprende la organización de estos valores como: <obligatorio $>$, $<$ prohibido $>$, $<$ permitido $>$, <opcional $>$. En la tabla 6 se da cuenta, entonces, de la zona modal deóntica:

Tabla 6. Valores deónticos: $<$ obligatorio>: normas o reglas sociales

\begin{tabular}{|c|c|}
\hline $\begin{array}{c}\text { < obligatorio } \\
\text { <deber hacer }\end{array}$ & $\begin{array}{c}\text { obligatorio } ~ \\
\text { <prohibido }>\end{array}$ \\
\hline < obligatorio $~$ \\
<permitido $>$ & $<\sim$ obligatorio $>$ \\
\hline
\end{tabular}

Fuente: Galatanu, 2003b.

\section{La zona modal de los valores de juicio de verdad}

Los valores modales que constituyen esta zona remiten tanto a los valores epistémicos como a los doxológicos. En el momento en que el hablante convoca estos valores en su discurso, estos dan cuenta de su construcción de la representación del mundo de ese sujeto pensante. Los epistémicos se refieren a seguro/certero/cierto, a lo incierto, lo probable, lo improbable, lo que funge como mediación y lo que no cumple esa función. Los valores epistémicos aluden al saber, al conocimiento y a la certeza que de ello tiene el sujeto y, por este hecho, son menos subjetivos que los doxológicos.

Los valores modales epistémicos se estructuran sobre el término cierto y gracias a la inserción de negación se obtienen estos valores, tal como lo muestra la tabla 7 :

Tabla 7. La base de los valores epistémicos

\begin{tabular}{|c|c|}
\hline Cierto & $\begin{array}{c}\text { Dudoso /cuestionable } \\
\text { (No cierto) }\end{array}$ \\
\hline $\begin{array}{c}\text { Probable/plausible } \\
\text { (Indeciso) } \\
\text { (No cierto que no) }\end{array}$ & $\begin{array}{c}\text { Excluido } \\
\text { (Cierto que no) }\end{array}$ \\
\hline Fuente: Darrault, 1976; Galatanu, 2000.
\end{tabular}

De lo expuesto se obtiene la tabla 8 que da cuenta de los valores epistémicos:

Tabla 8. Los valores epistémicos

\begin{tabular}{|c|c|}
\hline $\begin{array}{l}<\text { cierto }> \\
<\text { cierto }>\end{array}$ & $\begin{array}{l}<\text { cierto > } \\
<\text { excluido }>\end{array}$ \\
\hline $\begin{array}{c}<\sim \text { cierto > } \\
<\text { probable }>\end{array}$ & $\begin{array}{l}<\sim \text { cierto> } \\
<\text { incierto }>\end{array}$ \\
\hline
\end{tabular}

Fuente: Galatanu, 2003b.

Los valores doxológicos, menos objetivos que los epistémicos, se relacionan con las creencias y se actualizan mediante la aparición del verbo creer/ no creer. 
Aunque para algunos, la verdad no se construye únicamente sobre certezas, sobre el saber, sino igualmente se funda sobre lo que se cree en relación con los otros y con el mundo, los valores doxológicos se oponen a los epistémicos. Ya sea porque las creencias se oponen a los saberes o porque hacen parte de un estadio previo, de un paso, que es quizá necesario en el desarrollo y la consolidación de estos saberes. En torno a esto, Tardif manifiesta que

Opiniones y clichés, representaciones cotidianas y aparentemente creíbles, evidencias del sentido común, prejuicios, soluciones espontáneas, respuestas de cajón, pre-nociones, etc., constituyen lo que se denomina tradicionalmente la doxa, término griego que significa aproximadamente opinión, y que se opone a la episteme, es decir, al saber científico. (1988, p. 152)

\section{La zona modal axiológica}

La zona modal de lo axiológico ha sido la modalidad menos estudiada por la lingüística y no es el objeto de la lógica modal (Galatanu, 2003b, p. 95). Los valores modales que se encuentran en esta zona corresponden al sistema de valores, el cual toma forma en una suerte de normas que rigen, que orientan los comportamientos de los individuos. Esta zona modal corresponde a la idea de preferencia, de ruptura, y permite, por lo tanto, realizar evaluaciones de lo vivido por el hombre, de su experiencia. Las formas modales que se impregnan de estos valores conciernen a lo individual y a lo colectivo. En el terreno de lo axiológico, aparecen estos valores:

- Éticos-morales: Este campo de valores se estructura entre los polos $<$ bien $>$ y $<$ mal $>$.

- Estéticos: Estos valores remiten a lo que se presenta como agradable al individuo, al hablante, y a su relación con las concepciones de belleza y de fealdad. Este conjunto de valores corresponde a la lógica binaria $<$ bello $>\mathrm{y}<$ feo $>$.

- Pragmáticos: Referidos a la acción y a los resultados obtenidos en su comparación con los propósitos, los objetivos definidos y los medios comprometidos para su logro. Estos valores corresponden a las lógicas binarias $<$ útil $><$ inútil $>,<$ rentable $><$ no rentable $>$, $<$ eficaz $><$ ineficaz $>$.

- Intelectuales: Conciernen el interés que el sujeto puede tener por la realidad y se fundan sobre la actividad cognitiva que permite juzgar o estimar algo como $<$ interesante $><$ no interesante $>$.

- Hedónicos-afectivos: Estos valores se refieren a la afectividad del sujeto que comunica y dan cuenta del placer, la ausencia de placer, los sentimientos, las emociones. Estos valores se representan con lo siguiente: $<$ feliz $><$ infeliz $>$.

\section{La zona modal de los valores finalizantes}

Los valores finalizantes, o de juicio de intención, aparecen en el extremo del polo subjetivo, sobre el eje evaluativo en el que se mueve el sujeto. Estos valores designan la intención, el deseo y la voluntad. Esta zona cubre los valores volitivos (el querer, la voluntad) y los desiderativos (el deseo/desear).

Los valores volitivos se encuentran en relación con la capacidad individual de fijarse o imponerse objetivos por alcanzar, de establecer metas, de definir el interés por lograr un mejoramiento de sí mismo, una transformación de su ser y de sus acciones. Estos valores se construyen sobre la voluntad y su correspondiente toma de decisiones.

Las zonas semánticas modales que se exponen en los párrafos anteriores están situadas en un eje de apreciación o de evaluación/valoración, cuyos polos se orientan uno hacia los valores más subjetivos (finalizantes) y el otro hacia los valores más objetivos (ontológicos). Este movimiento de valores, vinculados a las entidades léxicas y movilizados y actualizados en el discurso, puede ilustrarse así (figura 1 ): 
Figura 1. La función discursiva

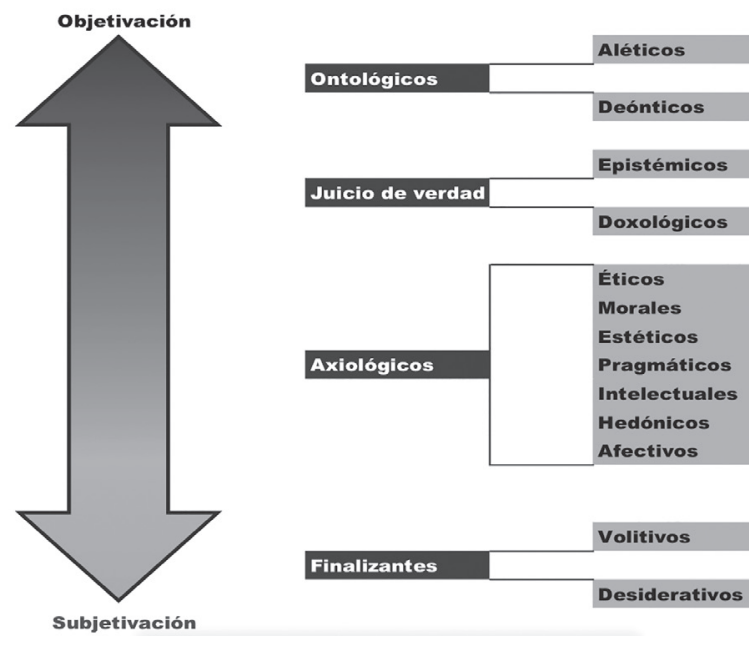

Fuente: Galatanu, 1996.

En este campo de las modalidades, Galatanu (2003b, p. 99) hace unas precisiones a partir de los desarrollos teóricos de la argumentación en la lengua (Anscombre y Ducrot, 1994), de los topoï y de las formas tópicas (Anscombre, 1995), así como de la semántica argumentativa (Carel y Ducrot, 1999). Galatanu expone que lo no-modal no existe en el discurso puesto que todo enunciado es argumentativo y, por lo tanto, existirá siempre una toma de posición por parte del sujeto hablante en condiciones discursivas "normales". Esto señala la importancia de los valores modales expresados por el significado de las entidades lingüísticas. Cuando estas unidades lingüísticas aparecen en el discurso, los mecanismos lingüísticos que dan soporte a la función argumentativa del sentido discursivo son diferentes de una entidad léxica a otra, en otras palabras “la autorización' de ciertos encadenamientos discursivos y 'la prohibición' de otras cadenas discursivas no están inscritas en el significado léxico de la misma manera, ni en el mismo nivel, en todas las unidades léxicas" (Galatanu, 2003b, p. 99).

\section{Consideraciones metodológicas}

Para efectos de analizar las consideraciones metodológicas que implica la SPA, se hace necesario aclarar la diferencia que se establece entre la construcción del significado léxico y la reconstrucción de la representación de este significado que poseen los hablantes. Estos dos procesos están ligados, respectivamente, al uso de los diccionarios representativos de una lengua (materna o extranjera) en la que se desea hacer la investigación, y a las informaciones que provienen de los sujetos sociales de interés del estudio. Si bien se han propuesto mecanismos de identificación y de reconstrucción similares, existen también diferencias que permiten distinguir claramente estas acciones.

El recurrir a los diccionarios permite dar cuenta de los significados que una sociedad, que una comunidad lingüística, ha forjado/aceptado a lo largo del tiempo y que, en un momento determinado, aparecen como lo que todos comparten para tener una comunicación adecuada en la lengua compartida. En este sentido, el diccionario es un referente del significado léxico y por esa razón es uno de los aspectos a los que se recurre en la SPA para el desarrollo de sus investigaciones. Sobre la base del discurso lexicográfico, esta propuesta teórica elabora o construye el significado léxico, para lo cual asume como hipótesis de trabajo que el significado léxico está conformado por el núcleo, los estereotipos, los posibles argumentativos y los despliegues argumentativos, según lo expuesto párrafos atrás.

De otro lado, luego de construir el significado léxico, se procede a reconstruirlo a partir de las representaciones de los hablantes de una comunidad. Para llevar a buen término esta segunda actividad, el investigador debe elaborar unos instrumentos, en este caso cuestionarios, que buscan identificar las representaciones que los sujetos asocian a la entidades léxicas, así como los valores inscritos en estas palabras. Para ello, se torna imperativo elaborar, entonces, algunas instrucciones que permitan establecer el núcleo y los estereotipos a partir de las respuestas de los encuestados.

Una vez que se han recogido estos datos es preciso comparar el significado léxico con la representación del significado reconstruido a partir de las asociaciones de los informantes. Esto permitirá establecer, entre otros, la conformidad o no conformidad al protocolo semántico de la palabra, los 
mecanismos semánticos o pragmáticos que generan las modificaciones en los estereotipos, así como los valores inscritos en estas representaciones.

Como se anunció en párrafos anteriores, la SPA establece un protocolo de investigación que se estructura sobre una base metodológica investigativa mixta. Primero, se procede a recoger la información. ${ }^{9}$ Una vez obtenidos los datos, estos son objeto de cuantificación para, posteriormente, dar cuenta de las representaciones activadas y de los valores movilizados en las respuestas de los informantes.

De manera precisa, el análisis semántico corresponde a la construcción del objeto teórico denominado significado léxico (Galatanu, 2006, p. 132). Este objeto teórico se elabora a partir de hipótesis externas sobre el sentido de las ocurrencias en la movilización de las entidades léxicas. Para el efecto, se han establecido dos grandes etapas, tal y como se expone a continuación.

Una primera etapa da cuenta de la representación del significado léxico a partir de corpus lexicográficos. En este momento se analizan algunos de los diccionarios representativos de los que usan los docentes en ejercicio o que han usado en su proceso de formación; específicamente, para el caso en cuestión se recurrió a diccionarios como el drae, el due y el Larousse, entre otros. Esta construcción del significado permitió determinar el núcleo y los estereotipos de la forma léxica tarea, así como los posibles argumentativos; esto, a la luz del discurso establecido como base orientadora de los hablantes de la lengua española, específicamente de los docentes del área de lengua (materna y extranjera) de Bogotá. Esta labor posibilita, además, precisar los elementos estables en el significado, así como aquellos más susceptibles de modificaciones, en cuanto son conjuntos abiertos (estereotipos). Como resultado de este ejercicio, se plantea la siguiente construcción, que sigue en proceso de elaboración:

En cuanto al núcleo o bloques constituidos por los elementos estables del significado, se tiene lo siguiente:

Tarea (escolar)

$\mathrm{N}$ : Sustantivo f.

Obra y trabajo obligatorios PLT dificultad PLT esfuerzo SE tiempo limitado PLT resultado

En lo que concierne a los estereotipos o asociaciones de los elementos del núcleo con otras representaciones, se identificó entre otros los siguientes: Ejercicio, hacer en casa, oportunidad, exigencia, fatiga, afán, aprendizaje...

En la tabla 9 se exponen los dos estratos para dar cuenta de sus relaciones fundadas en argumentación interna:

Tabla 9. Representación del significado léxico del término tarea (escolar)

\begin{tabular}{|c|l|}
\hline $\begin{array}{c}\text { Obra y trabajo } \\
\text { obligatorios }\end{array}$ & $\begin{array}{l}\text { PLT ejercicio, deber, ocupación, hacer en casa, lectura, } \\
\text { escritura, proyecto, problema, práctica, construcción, } \\
\text { conjunto de actividades, secuencia, estructuración, } \\
\text { oportunidad }\end{array}$ \\
\hline PLT & $\begin{array}{r}\text { PLT penalidad, relación, gradación, exigencia, demanda } \\
\text { cognitiva }\end{array}$ \\
\hline PLT & $\ldots$ \\
Esfuerzo & PLT cuidado, fatiga, ansiedad \\
\hline SE & $\ldots$ \\
\hline Tiempo limitado & PLT afán \\
\hline PLT & $\ldots$ \\
\hline Resultado & $\begin{array}{l}\text { PLT resolución, perceptibilidad, medición, aprendizaje, éxito, } \\
\text { conocimiento, mejoramiento, destrezas, reafirmación... }\end{array}$ \\
\hline
\end{tabular}

Fuente: Elaboración propia.

9 Esta actividad, en el marco de este proyecto, se ha llevado a cabo de acuerdo con los estudios realizados por Galatanu en el laboratorio de investigación CoDiRe (Construction Discursive des Représentations linguistiques et culturelles) de la Universidad de Nantes, así como mediante instrumentos que han sido diseñados y validados por, al menos, 10 tesis de doctorado y de maestría desarrollados en el citado laboratorio. 
$\mathrm{Al}$ retomar lo referido a la construcción del significado léxico, se hace necesario recordar que esta proviene de las definiciones identificadas en los diccionarios antes citados. Asimismo, en el núcleo de esta entidad léxica se observan cinco bloques de significado vinculados mediante los conectores virtuales PLT (Por Lo Tanto) y se (Sin Embargo), los cuales representan relaciones normativas y transgresivas, respectivamente. Cada uno de los elementos del núcleo se relaciona con los estereotipos como en el caso obra y trabajo obligatorios PLT ejercicio, gradación, exigencia, demanda cognitiva, fatiga $S E$ fracaso... en una argumentación interna. Esto lleva a determinar que se puede, en una argumentación externa, asumir la tarea escolar como asociada a ejercicio, gradación, exigencia, demanda cognitiva, fatiga SE fracaso...

Otro momento del análisis corresponde a la identificación de los valores presentes en cada uno de los elementos tanto del núcleo $(N)$ como de los estereotipos. En la tabla 10 se relacionan algunos de los valores vinculados a estas entidades lingüísticas presentes en las definiciones de la palabra tarea:

Tabla 10. Los valores presentes en el núcleo de tarea escolar

\begin{tabular}{|c|c|}
\hline $\begin{array}{c}\text { Elementos } \\
\text { del } \mathbf{N}\end{array}$ & \begin{tabular}{c} 
Valores vinculados \\
\hline Obligatorio
\end{tabular} \\
\hline Dificultad & $\begin{array}{c}\text { Deóntico } \\
\text { Pragmático +/-, } \\
\text { intelectual, hedónico-afectivo }\end{array}$ \\
\hline Esfuerzo & Hedónico-afectivo negativos \\
\hline Tiempo limitado & Hedónico-afectivo +/- \\
\hline Resultado & Pragmático +/- \\
\hline
\end{tabular}

Fuente: Elaboración propia.

Una primera mirada, con el propósito de determinar la preponderancia de valores presentes en el núcleo, revela que prevalece la zona modal axiológica y específicamente los valores hedónico-afectivos (positivos, negativos y ambivalentes) y los pragmáticos (ambivalentes). Es revelador el número mínimo de valores deónticos ligados a la obligatoriedad de la tarea escolar, el cual caracteriza de manera marcada esta actividad, pero que se asocia estrechamente con los valores axiológicos negativos.

Asimismo, es indispensable dar cuenta de los valores presentes en los estereotipos detectados en los diccionarios. A continuación se exponen algunos de los estereotipos y sus valores (tabla 11):

Tabla 11. Los valores presentes en los estereotipos de tarea escolar

\begin{tabular}{|c|c|}
\hline Estereotipos & Valores vinculados \\
\hline $\begin{array}{l}\text { Ejercicio } \\
\text { (mental o físico) } \\
\text { Deber } \\
\text { Ocupación } \\
\text { Hacer en casa } \\
\text { Lectura } \\
\text { Escritura } \\
\text { Proyecto } \\
\text { Problema } \\
\text { Práctica } \\
\text { Construcción } \\
\text { Conjunto de } \\
\text { actividades } \\
\text { Secuencia } \\
\text { Estructuración } \\
\text { Oportunidad }\end{array}$ & $\begin{array}{l}\text { Deóntico, pragmático, intelectual } \\
\text { Deóntico } \\
\text { Pragmático, epistémico, intelectual } \\
\text { Deóntico, pragmático, hedónico-afectivo } \\
\text { +/- } \\
\text { Pragmático, intelectual, epistémico } \\
\text { Pragmático, intelectual, epistémico } \\
\text { Pragmático, intelectual, epistémico } \\
\text { Epistémico, intelectual, hedónico-afectivo } \\
\text { Pragmático, epistémico } \\
\text { Pragmático, intelectual }\end{array}$ \\
\hline
\end{tabular}

Fuente: Elaboración propia.

En estas entidades léxicas, que se asocian con el primer bloque de significado del núcleo, se identifica una primacía de los valores pragmáticos (12), los epistémicos (9) y los intelectuales (7). Estas zonas modales revelan un incremento del carácter útil de los estereotipos asociados a tarea, así como de aquellos ligados al interés de las acciones y de los ejercicios que actualizan la tarea a la luz de los diccionarios. A diferencia de lo identificado en el núcleo, se hace significativa la zona modal epistémica que da cuenta del aprendizaje, del saber, del conocimiento, lo cual es mínimo entre los elementos estables del significado léxico de la tarea. Contrasta la disminución significativa, de manera proporcional al número de elementos presentes, de los valores hedónico-afectivos vinculados por los estereotipos y que están asociados al trabajo en casa, a los problemas (asignados) y a la oportunidad de aprender. 
La segunda etapa se refiere a la identificación de las ocurrencias relacionadas con la palabra tarea y que tienen lugar en un discurso definido y delimitado: la movilización discursiva de los encuestados. Para este caso, la muestra estuvo conformada por 119 docentes de instituciones educativas de Bogotá, que se desempeñan en el área de lengua materna o extranjera, en los diferentes ciclos. En esta etapa se busca dar cuenta tanto de las representaciones léxicas como de la valoración activada en ellas, así como el cinetismo del significado léxico identificados en el discurso de los docentes. Para obtener esta información se recurre a cuestionarios que permiten identificar:

- Los elementos estables del significado léxico.

- Los elementos que constituyen conjuntos abiertos o estereotipos.

- La orientación axiológica presente en las ocurrencias.

Los cuestionarios aparecen como instrumentos de recolección de información apropiados para la identificación de las representaciones sociales. Los datos recogidos gracias a la aplicación de estas herramientas se tratan mediante el análisis prototípico y categorial que permite establecer las asociaciones libres más cercanas al núcleo (del significado léxico) y aquellas situadas en la periferia y que dan cuenta de los estereotipos como conjunto abierto y con mayor exposición al cinetismo. Con el fin de tener acceso a estas representaciones, el cuestionario empleado está constituido por estos dos apartados, que forman parte habitualmente del protocolo de la SPA:

a. Determinación de los estereotipos asociados a la entidad léxica tareas escolares, datos que se obtienen gracias a la presentación de formas léxicas que los informantes relacionan con el término objeto de análisis.

b. Identificación del núcleo del significado léxico de la entidad tareas escolares, lo cual se logra mediante la definición propuesta por los informantes.
A las dos secciones anteriores, el grupo de investigación agregó una tercera que propone a los informantes una serie de encadenamientos argumentativos para que los valoren en función del carácter posible o imposible de esas cadenas argumentativas. Esta sección corresponde a características de un test de aceptabilidad de asociaciones de palabras en secuencias argumentativas.

Atendiendo a los elementos anteriores, el cuestionario está conformado por una pregunta de carácter asociativo en la que se solicita al informante que escriba todas las palabras relacionadas con el término tarea. De las respuestas de los 119 docentes se obtienen los estereotipos que ellos vinculan a la tarea. En la segunda pregunta se propone a los encuestados evaluar una serie de encadenamientos argumentativos para determinar si los consideran posibles o imposibles. Esto permitirá comparar esas respuestas con las formuladas en las otras secciones del cuestionario y enriquecer las posibilidades de análisis. En la tercera pregunta se les pide a los informantes que redacten una definición de tarea. Los datos que resultan de esta sección son un elemento fundamental para la elaboración del núcleo de la entidad léxica. Por último, la cuarta pregunta propone al grupo de docentes una situación sobre las tareas para que estos reaccionen y justifiquen sus respuestas. Estas reacciones y su argumentación permiten identificar la movilización discursiva de valores y la aparición de nuevas representaciones asociadas a la palabra tarea (escolar).

Sobre la información obtenida de este cuestionario se procede al tratamiento descriptivo y analítico ${ }^{10}$ de la muestra, con base en las ocurrencias más altas, y de los valores mayoritariamente movilizados, las posibilidades de reconstrucción del significado de tarea (escolar) y de su relación con las prácticas sociales de los docentes encuestados.

Con respecto a los estereotipos, una vez analizados los datos por medio del cuestionario aplicado, se han establecido 69 unidades léxicas que los 119 profesores encuestados asocian con la palabra tarea, como se expone a continuación (tabla 12):

10 Cabe señalar que las actividades de normalización y de conteo de las ocurrencias léxicas se efectuaron con ayuda del programa de análisis léxico Lexico 3. 
Tabla 12. Los estereotipos de tarea escolar

\begin{tabular}{|c|c|c|}
\hline refuerzo & aplicación & reto \\
\hline trabajo & desarrollo & análisis \\
\hline ejercicio & proceso & habilidad \\
\hline actividad & complemento & solución \\
\hline responsabilidad & tiempo & asociación \\
\hline aprendizaje & profundización & apoyo \\
\hline consulta & indagación & estrategia \\
\hline compromiso & ayuda & extra \\
\hline práctica & evaluación & ocupación \\
\hline investigación & casa & oficio \\
\hline repaso & disciplina & aclaración \\
\hline autonomía & taller & descubrimiento \\
\hline esfuerzo & cumplimiento & ejercitación \\
\hline labor & relación & interacción \\
\hline retroalimentación & reflexión & objetivo \\
\hline dedicación & motivación & posibilidad \\
\hline obligación & comprensión & saber \\
\hline asignación & creatividad & elaboración \\
\hline oportunidad & exigencia & padres \\
\hline conocimiento & lectura & revisión \\
\hline deber & dificultad & problema \\
\hline afianzamiento & apropiación & planeación \\
\hline mejoramiento & enseñanza & concepto \\
\hline
\end{tabular}

Fuente: Elaboración propia

La distribución porcentual de los estereotipos identificados, especialmente los de mayor ocurrencia, se puede apreciar en la siguiente gráfica (figura 2):

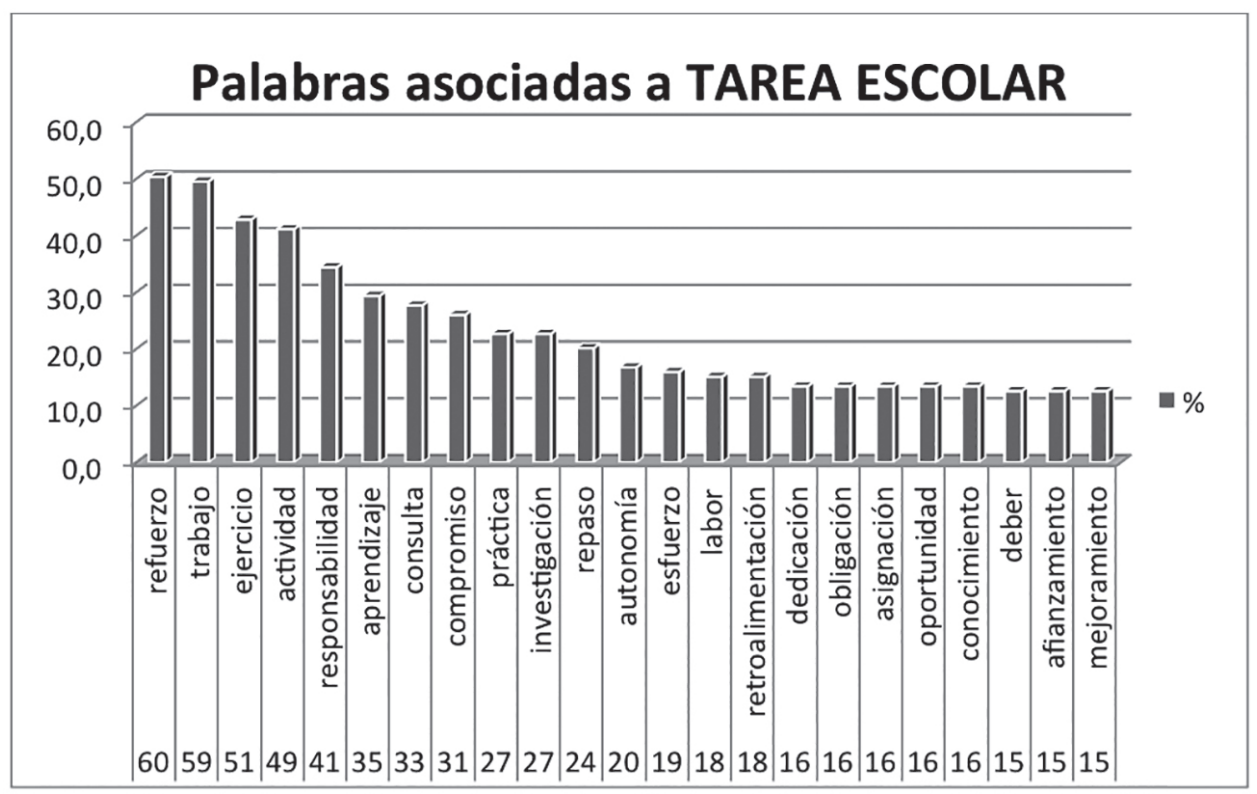

Fuente: Elaboración propia. 
Universidad Pedagógica Nacional

Facultad de Humanidades

Ahora bien, al identificar los valores movilizados en las entidades léxicas de mayor ocurrencia en las asociaciones de los encuestados, se encuentran los siguientes (tabla 13):

Tabla 13. Los valores movilizados en los estereotipos de los docentes

\begin{tabular}{lc} 
Deónticos & 17 \\
Pragmáticos & 17 \\
Epistémicos & 15 \\
Aléticos & 14 \\
Hedónico-afectivos & 14 \\
Intelectuales & 11 \\
Volitivos & 6 \\
Morales & 4 \\
Éticos & 3 \\
Desiderativos & 2 \\
\hline
\end{tabular}

Fuente: Elaboración propia.

La comparación de estos valores, y su número, con los que hasta la elaboración de este documento se han establecido en los diccionarios, permite determinar que existe una marcada coincidencia en lo que respecta a las zonas modales pragmática, epistémica e intelectual, que son las más salientes entre los estereotipos presentes en el significado según los discursos lexicográficos. De otro lado, se advierte unas diferencias importantes entre los dos grupos de estereotipos (en el discurso lexicográfico y en los datos de los informantes). Existe una alta movilización de valores deónticos y aléticos en las representaciones de los docentes, lo cual contrasta con la débil presencia de estos en el protocolo semántico de la palabra tarea (escolar). Esta característica del discurso de los docentes da cuenta de la naturaleza que le asignan a la tarea como actividad obligatoria y necesaria para la corroboración de aprendizajes o para favorecerlos, de ahí el alto número de valores ontológicos.

Asimismo, resaltan los valores hedónico-afectivos vinculados a la tarea mediante las asociaciones propuestas por los docentes y esto en comparación con la baja cantidad de esos mismos valores de la zona axiológica presentes en los diccionarios. Se puede afirmar que estos valores, ambivalentes, se movilizan a partir de los trabajos, los ejercicios, las labores y los repasos, entre otros, impuestos a los estudiantes como una obligación, como deberes que les representan esfuerzo y este, a su vez, fatiga $\mathrm{y}$ reacciones y acciones variadas.

En relación con la identificación de los elementos del núcleo, una vez analizados los datos por medio del cuestionario aplicado, se encontró, en un primer momento, una serie de constantes en las respuestas de los encuestados, las cuales se orientan hacia temáticas que favorecerán la determinación del núcleo en la reconstrucción del significado léxico en el corpus de los docentes. Entre las temáticas sobresalen las que se estructuran alrededor de: estudiante, actividad, aprendizaje, conocimiento, clase, tema, objetivo, oportunidad, ejercicio, proceso, refuerzo, trabajo y casa.

A manera de ilustración se expone a continuación (cuadro 1) el caso de la temática oportunidad, que, sin ser la que corresponde a la de mayor ocurrencia entre las respuestas de los docentes, permite revelar la complejidad de las actividades por realizar para establecer el núcleo del significado de tarea, a la luz de los encuestados: 
Cuadro 1. La tarea (escolar) como oportunidad según los docentes de Bogotá

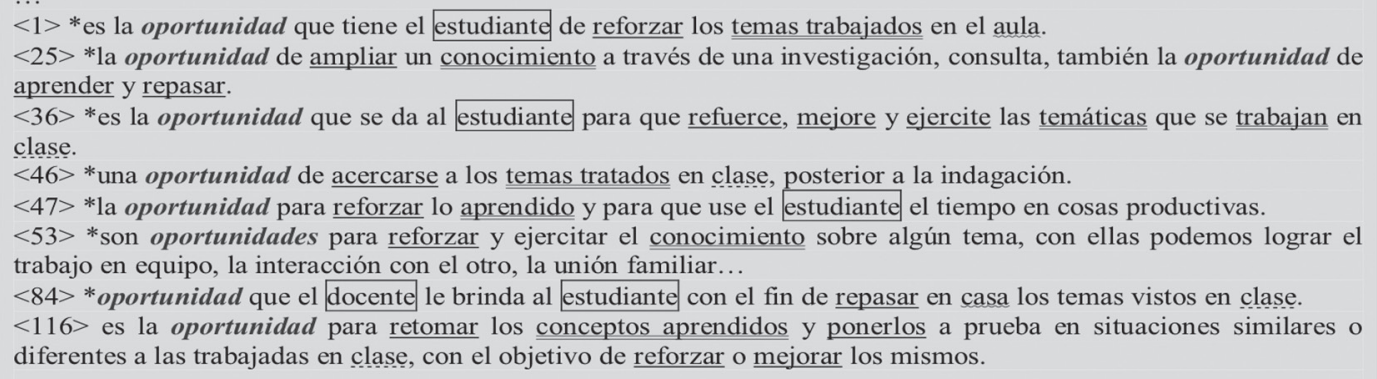

Fuente: Elaboración propia.

Una primera acción corresponde a la identificación de las precisiones y de las relaciones que se establecen en el marco de cada temática observada, lo que se traduce de manera aproximada como se expone a continuación (tabla 14):

Tabla 14. Precisiones sobre la temática oportunidad como tarea escolar

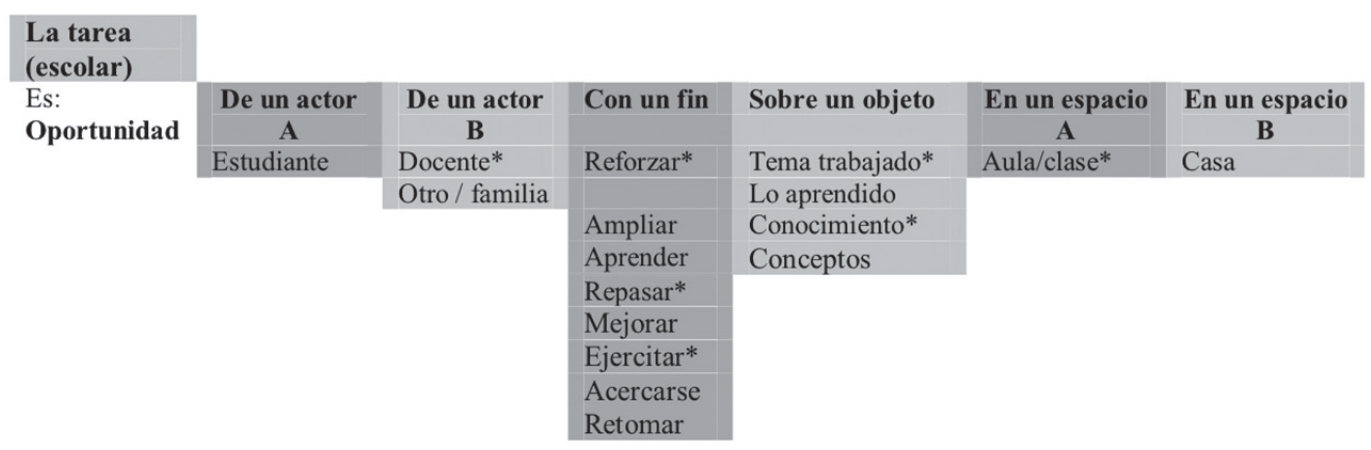

Fuente: Elaboración propia.

A partir de los cuadros anteriores, y además de abordar lo referido a las temáticas, es preciso determinar los movimientos de objetivación y subjetivación en las respuestas de los informantes, así como la axiologización presente en los corpus.

En ese orden de ideas, el estudio de las etiquetas nominales y de las verbales que dan forma a las modalidades de re, junto con sus respectivos modificadores, revela que en el corpus anterior prevalece un movimiento de objetivación soportado por cerca de 36 de esas etiquetas, tales como estudiante, profesor, tema, conocimiento, clase, casa...Los modificadores (caractérisants, en francés) de las etiquetas nominales y los modificadores de las verbales son muy poco significativos. Cabe señalar que estos modificadores contribuyen al movimiento de subjetivación.

Por otra parte, en ese mismo corpus que da origen a la temática oportunidad, los valores vinculados a la expresión de los docentes ponen de relieve un leve equilibrio entre los valores que se orientan hacia el polo objetivo (ontológicos) y aquellos que apuntan al polo subjetivo (axiológicos), es decir, aproximadamente 27 y 29, respectivamente. Prevalecen los valores deónticos (ontológicos) sobre los epistémicos (juicio de verdad) y los aléticos (ontológicos). En la zona modal axiológica se identifica una preponderancia de los valores pragmáticos sobre los intelectuales. Esta cercanía de la cantidad de valores objetivos y subjetivos movilizados da cuenta del carácter obligatorio y necesario de la tarea escolar y de su utilidad, según los encuestados, en el mejoramiento de temáticas y conocimientos a los que fueron expuestos los estudiantes.

\section{Algunos aspectos a manera de conclusión}

Lo expuesto en los párrafos anteriores ilustran algunos de los aspectos del protocolo investigativo propuesto por la SPA y desarrollado en algunos de 
los componentes del marco teórico. Igualmente, enfatiza, mediante el desarrollo y la presentación de algunas de las etapas en curso, en la complejidad del análisis y de los aportes de esta orientación de las ciencias del lenguaje a las ciencias de la educación, específicamente al estudio de este componente de la acción docente. En este orden de ideas, hasta el momento, este trabajo investigativo pone de manifiesto la diversidad de concepciones que tienen los docentes de los cinco ciclos de la educación de Bogotá, así como los valores entre los que priman los deónticos y los pragmáticos en el núcleo de la tarea escolar, y entre los que escasean los finalizantes. Prevalecerían, entonces, las representaciones de los profesores (¿y su carácter institucional?) sobre el interés y la acción de los estudiantes (¿y de padres?).

\section{Referencias}

Anscombre, J.-C. (1995). Théorie des topoï. Paris: Kimé.

Anscombre, J.-C., y Ducrot, O. (1994). La argumentación en la lengua. Madrid: Gredos.

Calsamiglia, H., y Tusón, A. (1999). Las cosas del decir: Manual de análisis del discurso. Barcelona: Ariel.

Carel, M., y Ducrot, O. (1999). Le problème du paradoxe dan sunesé mantique argumentative. Langue Française, 123, 6-26.

Carel, M., y Ducrot, O. (2005). La Semántica argumentativa: Una introducción a la teoría de los bloques semánticos. Buenos Aires: ColihueUniversidad.

Darrault, Y. (1976). Présentation. Langage, 10(43), 3-9.

Dervin, F. (2009). Approches dialogiques et énonciatives de l'interculturel: pour une didactique des langues et de l'identité mouvante des sujets. Synergies Roumanie, 4, 165-178.

Galatanu, O. (1996). Analyse des discours et approche des identités. Revue Education Permanente, (128), 45-61.

Galatanu, O. (2000). Langue, Discours et systèmes de valeurs. En E. Suomela-Salmi, Curiosités linguistiques (pp. 80-102). Turku: Université de Turku.

Galatanu, O. (2000a). Signification, senset construction discursive de soi et du monde. En J.-M. Barbier y O. Galatanu (dir.), Signification, Sens, formation (pp. 25-43). Paris: PUF.

Galatanu, O. (2002). Le concept de modalité: les valeurs dans la langue et dans le discours. En O. Galatanu y
F Le Roy (Eds.), Les Valeurs, Séminaire le Lien Social, 0 (0), (pp. 17-32).

Galatanu, O. (2003a). La sémantique des possibles argumentatifs et ses enjeux pour l'analyse du discours. El texto como encrucijada: estudios franceses y francófonos, 2, 213-226. Recuperado de http://dialnet. unirioja.es/servlet/articulo?codigo $=1011551$

Galatanu, O. (2003b). La construction discursive des valeurs. En J.-M. Barbier (dir.), Valeurs et activités professionnelles. Séminaire du Centre de Recherche sur la Formation du CNAM (pp. 87-114). Paris: L'Harmattan.

Galatanu, O. (2005a). Analyse du discours. Diversité Ville, école, intégration, 140, 55-61. Recuperado en http://www.cndp.fr/archivage/valid/70174/7017410778-13726.pdf

Galatanu, O. (2005b). La "stéréophagie" un phénomène discursif de déconstruction-reconstruction de la signification lexicale. Les Actes du Colloque International Représentation du sens linguistique III-RSL III, 189-207.

Galatanu, O. (2006). Le cinétisme de la signification lexicale. En J.-M. Barbier y M. Durand (ed.), Sujets, activité, environnement. Paris: Presses Universitaires de France.

Galatanu, O. (2007). Sémantique des possibles argumentatifs et axiologisation discursive. En D. Bouchard y J. Evrard (ed.), Représentation du sens linguistique, 2, 313-325.

Galatanu, O. (2009a). L’Analyse du Discours dans la perspective de la Sémantique des Possibles argumentatifs: les mécanismes sémantico-discursifs de construction du sens et de reconstruction de la signification lexicale. Cahiers du Laboratoire de Recherche sur le Langage, (2), 49-68.

Galatanu, O. (2009b). Les incidences sémantiques des déploiements argumentatifs dépendants du co-(n) texte de production du discours. Mémoires de la Société Néophilologique de Helsinki (LXXVIII), 391-404.

Putnam H. (1975). The meaning of "meaning". Philosophophical papers, 2, 215-271.

Ruiz, J. (2011).La mobilisation discursive des valeurs sociales chez les futurs enseignants de FLE en Colombie. Nantes: Universidad de Nantes.

Tardif, M. (1988). Le chercheur et les contraintes doxologiques. Revue des sciences de l'éducation, 14(2), 149-163.

Vignaux, G. (1988). Le discours, acteur du monde: Enonciation, argumentation et cognition. Paris: Ophrys. 